\title{
Prolonged Seizures Recruit Caudal Subventricular Zone Glial Progenitors Into the Injured Hippocampus
}

\author{
Jack M. Parent,$^{1^{*}}$ Nicolas von dem Bussche, ${ }^{2}$ and Daniel H. Lowenstein ${ }^{2}$
}

\begin{abstract}
Neurogenesis persists in the adult rat rostral forebrain subventricular zone (SVZ) and is stimulated by status epilepticus (SE). More caudal SVZ (cSVZ) neural progenitors migrate to the hippocampus after ischemic injury and contribute to CA1 pyramidal cell regeneration. Because SE also damages the hippocampus, we examined the effects of SE on cSVZ precursors. SE was induced in adult rats with pilocarpine, and cell proliferation in cSVZ and hippocampus was examined by bromodeoxyuridine (BrdU) and retroviral reporter labeling. Neural precursors were assayed by immunostaining for specfic markers between 1 and 35 days after SE. BrdU-positive cells labeled prior to SE markedly increased in numbers within 1-2 weeks in the cSVZ and infracallosal region, but not in the corpus callosum. Doublecortin-, polysialic acid neural cell adhesion molecule-, and TUC-4 (TOAD/Ulip/CRMP family4)-immunostained cells with migrating morphology increased with a similar time course after SE and extended from the cSVZ to CA1 and CA3 regions. Retroviral reporters injected into the $\mathrm{CSVZ}$ of controls showed labeled cells with oligodendroglial morphology located in the cSVZ and corpus callosum; when injected 2 days prior to SE, many more reporter-labeled cells appeared several weeks later and were located in the cSVZ, corpus callosum, and hippocampus. Labeled cells showed glial morphologies and expressed astrocyte or oligodendrocyte markers. Neither BrdU- nor retroviral reporter-labeled cells coexpressed neuronal markers in controls or pilocarpine-treated rats. These results indicate that SE increases cSVZ gliogenesis and attracts newly generated glia to regions of hippocampal damage. Further study of seizure-induced gliogenesis may provide insight into mechanisms of adult neural progenitor regulation and epileptogenesis. $\odot 2006$ Wiley-Liss, Inc.
\end{abstract}

KEY WORDS: $\quad$ neural stem cell; gliogenesis; epileptogenesis; pilocarpine; hippocampus

\section{INTRODUCTION}

Neural progenitors persist in the adult mammalian forebrain subventricular zone (SVZ) and hippocampal dentate gyrus (DG) (Altman and Das, 1965; Altman, 1969; Kaplan and Hinds, 1977; Bayer, 1983; Cameron et al., 1993; Lois and Alvarez-Buylla, 1994; Kuhn et al., 1996; Eriksson et al., 1998; Gould et al., 1998; Kornac and Rakic, 1999). In the adult rodent, SVZ progenitors generate olfactory bulb interneurons and DG progenitors give rise predominantly to dentate granule cells

\footnotetext{
${ }^{1}$ Department of Neurology, University of Michigan Medical Center, Ann Arbor, Michigan; ${ }^{2}$ Department of Neurology, University of California, San Francisco, California

*Correspondence to: Jack M. Parent, M.D., Department of Neurology, University of Michigan Medical Center, 4412E Kresge III Building, 200 Zina Pitcher Place, Ann Arbor, MI 48109-0585.

E-mail: parent@umich.edu

Accepted for publication 1 November 2005

DOI 10.1002/hipo.20166

Published online 24 January 2006 in Wiley InterScience (www.interscience. wiley.com).
}

(Bayer, 1983; Cameron et al., 1993; Kuhn et al., 1996; Luskin, 1998). Less well studied are neural progenitors in the SVZ that develop into glia. These progenitors extend to the caudal SVZ (cSVZ) of the lateral ventricle and in neonatal or juvenile rodents give rise to white matter astrocytes and oligodendrocytes, or their precursors (Levison et al., 1993, 1999). The capacity for SVZ progenitors to generate glia in the adult is uncertain (Picard-Riera et al., 2004).

Seizure-induced injury increases neurogenesis in both the DG and SVZ-olfactory bulb pathway (Parent et al., 1997, 1998, 2002; Bengzon et al., 1997; Gray and Sundstrom, 1998; Scott et al., 1998). Prolonged seizures also induce the ectopic migration of neuroblasts to damaged regions (Parent et al., 1997, 2002a, 2005). Rostral SVZ neuronal precursors that migrate aberrantly after seizures or other acute brain injuries may have reparative potential (Arvidsson et al., 2002; Parent et al., 2002a,b). Evidence suggests, however, that seizure-induced ectopic migration of dentate granule cell progenitors leads to aberrant neuronal integration that may be detrimental (Parent et al., 1997, 2005; Scharfman et al., 2000; Dashtipour et al., 2001).

Recent data indicate that neural progenitors in the adult rodent cSVZ migrate to regions of ischemic hippocampal damage and replace injured CA1 pyramidal neurons. Nakatomi and colleagues showed that delayed hippocampal CA1 pyramidal cell death induced by transient global ischemia in adult rat leads to replacement of damaged CA1 pyramidal neurons by endogenous neural progenitors (Nakatomi et al., 2002). At least a portion of these progenitors arose from the cSVZ (referred to as the posterior periventricle region). Brief intraventricular infusion of growth factors in the first week after stroke markedly increased regeneration and behavioral recovery, although others have found significant CA1 regeneration even in the absence of growth factor treatment (Bendel et al., 2005). These studies suggest that ischemic brain injury stimulates neurogenesis in otherwise dormant regions of the adult rodent brain, and raise the possibility that other forms of brain injury may also activate hippocampal self-repair mechanisms.

Prolonged seizures in the pilocarpine model of mesial temporal lobe epilepsy (TLE) (mTLE) increase rostral SVZ neurogenesis and cause hippocampal pyra- 
midal cell death (Turski et al., 1983; Parent et al., 2002a). We reasoned that, like ischemic injury, status epilepticus (SE)induced hippocampal damage may lead to a low-level of hippocampal pyramidal cell regeneration from cSVZ progenitors. We, therefore, examined the effect of pilocarpine-induced SE on cSVZ progenitors in adult rat. Bromodeoxyuridine (BrdU) labeling and retroviral reporter injections into the cSVZ were used to examine cell proliferation and migration. The phenotypes of newborn cells were determined by immunofluorescence double labeling and confocal microscopy. We found that SE increased cSVZ cell proliferation and induced ectopic migration of cSVZ neural progenitors to the injured hippocampus. The newborn cells, however, did not replace damaged pyramidal cells but instead differentiated exclusively into glia.

\section{METHODS}

\section{Pilocarpine-Induced SE}

Young adult, male Sprague Dawley rats (200-240 g) were pretreated with injections of atropine methylbromide $(5 \mathrm{mg} / \mathrm{kg}$, i.p.; Sigma, St. Louis, MO) and $15 \mathrm{~min}$ later were given pilocarpine hydrochloride $(340 \mathrm{mg} / \mathrm{kg}$, i.p.; Sigma) to induce SE. If seizure activity did not start within an hour after the initial pilocarpine injection, an additional dose of $170 \mathrm{mg} / \mathrm{kg}$ was given. Seizures were monitored behaviorally and then terminated after $2 \mathrm{~h}$ of focal convulsive SE (head and forelimb clonus) with diazepam (10 mg/kg, i.p.; Elkins-Sinn, Cherry Hill, $\mathrm{NJ}$ ); additional doses of $5 \mathrm{mg} / \mathrm{kg}$ diazepam were given at 45$60 \mathrm{~min}$ intervals if subtle seizure activity persisted. Control rats were treated identically except that $0.9 \%$ sodium chloride solution was substituted for pilocarpine. All procedures were approved by research oversight committees for the use and care of animals at the University of California, San Francisco and the University of Michigan Medical Centers.

\section{BrdU Labeling and Tissue Processing}

BrdU labeling was used to identify proliferating ( $S$ phase) cells and follow their disposition over time. BrdU $(50 \mathrm{mg} / \mathrm{kg}$; Roche, Indianapolis, IN) was administered intraperitoneally (i.p.) using two different protocols: (1) twice, $6 \mathrm{~h}$ apart, on day 7 after saline or pilocarpine treatment $(n=3-4 /$ time point for each group) and animals were perfused 2, 7, 14, or 28 days later $(9,14,21$, or 35 days after SE); or (2) twice, $6 \mathrm{~h}$ apart, on day 2 prior to pilocarpine or saline treatment $(n=3 /$ time point for each group), and rats were killed 3, 6, 9, 12, or 16 days later $(1,4,7,10$, or 14 days after SE). With the latter labeling regimen, BrdU incorporates into constitutively dividing cells that are subsequently exposed to the prolonged seizure episode. The influence of pilocarpine-induced SE on DGC neurogenesis using this "pre-seizure" BrdU labeling regimen has been described previously (Parent et al., 1999). Rats received an overdose of pentobarbital sodium (Abbott Laboratories, North Chicago, IL) and were transcardially perfused with phosphatebuffered saline (PBS) followed by $4 \%$ paraformaldehyde $(\mathrm{pH}$,
7.4; $360 \mathrm{ml}$ ). After postfixation in situ overnight, brains were removed, washed once in PBS, cryoprotected with 30\% sucrose in PBS, and frozen in powdered dry ice. Brains were sectioned coronally at $40 \mu \mathrm{m}$ thickness through the entire rostral-caudal extent of the hippocampal formation.

\section{Retroviral Reporter Injections}

Proliferating cells in the cSVZ were labeled specifically by injection of replication-incompetent retrovirus carrying nuclear localization signal $\beta$-galactosidase (nls- $\beta$-gal, GPGnlsLZ; a gift of Richard Mulligan, Harvard University, Cambridge, MA) or enhanced green fluorescent protein (LNIT-GFP; a gift of Fred Gage, The Salk Institute, La Jolla, CA) reporters. Vesicular stomatitis virus $G$ protein pseudotyped retrovirus was generated from 293GPG producer cells, the supernatant was collected, and the virus was concentrated and titered as described previously (Ory et al., 1996). Animals were anesthetized with i.p. ketamine $(70 \mathrm{mg} / \mathrm{kg})$ and xylazine $(8 \mathrm{mg} / \mathrm{kg})$, positioned in a stereotactic frame (Kopf Instruments, Tujunga, CA), and 1-1.5 $\mu \mathrm{l}$ of concentrated $\left(10^{8}-10^{9} \mathrm{cfu}\right.$ ) virus stock (with $80 \mu \mathrm{g} / \mathrm{ml}$ polybrene) was injected stereotactically into the cSVZ at the level of the dorsal hippocampus over $5 \mathrm{~min}$. Injection coordinates relative to bregma were $4.1 \mathrm{~mm}$ posterior and $5.0 \mathrm{~mm}$ lateral, at a depth of $3.1 \mathrm{~mm}$ from the brain surface. Injection sites were confirmed in processed tissue by visualizing the needle track. Adult rats were injected 2 days before pilocarpine $(n=7)$ or saline $(n=5)$ treatment, and animals were killed 11, 16, or 23 days after retrovirus injection $(9,14$, or 21 days after SE). Two additional rats injected with LNIT-GFP that received pilocarpine but did not experience convulsions were killed 16 days after retrovirus injection and considered as controls.

\section{Immunohistochemistry and Confocal Microscopy}

Diaminobenzidine peroxidase immunohistochemistry was performed on free-floating tissue sections or slides as described previously (Parent et al., 1997, 2002a). For BrdU immunostaining, DNA was denatured by incubating tissue sections in $2 \mathrm{~N} \mathrm{HCl}$ for $30 \mathrm{~min}$ at $37^{\circ} \mathrm{C}$ followed by a $10 \mathrm{~min}$ wash in $0.1 \mathrm{M}$ borate solution, $\mathrm{pH}$ 8.5. Tissue was incubated for 24-48 h in primary antibody at $4{ }^{\circ} \mathrm{C}$; antibody dilutions used were: 1:1,000 for BrdU (mouse monoclonal; Boehringer Mannheim, Indianapolis, IN), 1:5,000 for doublecortin (DCx; rabbit polyclonal, a gift of C. Walsh, Harvard University); and 1:5,000-10,000 for TUC-4 (TOAD/ULIP/CRMP-4; rabbit polyclonal, a gift of S. Hockfield, MA Institute of Technology). Single and double-label immunofluorescence histochemistry was done according to published methods (Parent et al., 2002a). Primary antibody dilutions used were: 1:200 for BrdU (rat monoclonal; Accurate Chemical, Westbury, NY); 1:500 for polysialylated neural cell adhesion molecule (PSA-NCAM; mouse IgM 5A5 clone; Developmental Studies Hybridoma Bank, University of Iowa); 1:10,000 for TUC-4; 1:200 for neuron-specific $\beta$-tubulin (TuJ1; mouse monoclonal; Babco, Berkely, CA); 1:1,000 for neuronal nuclear protein (NeuN; mouse monoclonal; Chemicon, Temecula, CA); 1:1,000 for myelin basic protein (MBP; rat monoclonal, Chemi- 
con); 1:500 for microtubule-associated protein 2 (MAP2; mouse monoclonal; Sigma), 1:200-500 for glial fibrillary acidic protein (GFAP; rat monoclonal, a gift of V. Lee, University of Pennsylvania; or rabbit polyclonal, Sigma); 1:2,000 for neurofilament-L (NF-L, gift of V. Lee); and 1:1,000 for $\beta$-gal (rabbit polyclonal; 5"-3 Prime, Boulder, CO). Secondary antibodies for immunofluorescence were goat antirat IgG conjugated to fluorescein isothiocyanate (FITC), Cy-5 or Texas Red, goat antimouse IgG conjugated to FITC, Texas Red or Alexa-594 (Molecular Probes), goat antirabbit IgG conjugated to FITC or Texas Red, and goat antimouse IgM conjugated to Texas Red (all species cross-adsorbed and from Jackson Immunoresearch Laboratories, West Grove, PA unless otherwise noted) at 1:400 dilutions. Tissue was incubated in secondary antibody overnight at $4{ }^{\circ} \mathrm{C}$. For double-label immunofluorescence using rat anti-BrdU and a second primary antibody, free-floating sections were incubated in the second primary antibody for $24 \mathrm{~h}$ at $4^{\circ} \mathrm{C}$, washed with Trisbuffered saline (TBS) $(0.15 \mathrm{M} \mathrm{NaCl}, 0.1 \mathrm{M}$ Tris-HCl, pH 7.6) for $45 \mathrm{~min}$, postfixed in $4 \% \mathrm{PFA}$ for $20 \mathrm{~min}$, rinsed 3 times with TBS, and denatured with $2 \mathrm{~N} \mathrm{HCl}$ as described above. After TBS washes and blocking, sections were incubated in rat antiBrdU antibody and the second primary antibody for another $24 \mathrm{~h}$ at $4^{\circ} \mathrm{C}$. Double- or triple-label immunofluorescence, images were obtained using a BioRad MRC 1024 (Hercules, CA) or Zeiss LSM 510 (Oberkochen, Germany) confocal laser microscope as $z$-series stacks (1.0 $\mu \mathrm{m}$ optical thickness), visualized with National Institutes of Health (NIH) Image version 1.61 software, and transferred to Adobe Photoshop for color merging (Adobe Systems, Mountain View, CA).

\section{Image Analysis and Statistical Comparisons}

Light microscopic images of coronal brain sections were acquired using a Leica DMIRB (Heidelberg, Germany) inverted microscope and SPOT-RT (SPOT Diagnostic Instruments, Sterling Heights, MI) digital camera. BrdU-immunoreactive cells in digitized images captured under a $20 \times$ objective were counted using a counting grid with the examiner blinded to experimental condition. One region of interest included the cSVZ adjacent to the caudal most aspect of the lateral ventricle at dorsal hippocampal levels and extending medially, covering the infracallosal region including the alveus and part of stratum oriens of CA1. The other region of interest included the midline corpus callosum. Counts were made from 3 rats/group using 5-6 sections (10-12 dentate gyri) spaced at least $240 \mu \mathrm{m}$ apart over the dorsal hippocampus. Statistical comparisons between groups for each region were made using a two-tailed Student's t-test. Analyses were performed with StatView software (Abacus Concepts, Berkeley, CA) and the significance level was set at $P<0.05$. For semiquantitative analysis of DCx expression in the cSVZ (Table 1), the magnitude of immunoreactivity was examined under $10 \times$ and $20 \times$ objectives and graded on a 5-point scale: -, no immunoreactivity; + , minimal immunoreactivity; ++ , moderate immunoreactivity in the cSVZ extending several cell layers in thickness infracallosally; +++ , strong immunoreactivity in the cSVZ and infracallosal region with some cells extending into CA1 and CA3;
TABLE 1.

Semiquantitative Analysis of DCx Expression in the cSVZ

\begin{tabular}{lcl}
\hline Condition & Numbers & DCx Score \\
\hline Control & 5 & + \\
7 d SE & 5 & ++ \\
14 d SE & 4 & +++ \\
35 d SE & 4 & + \\
\hline
\end{tabular}

Doublecortin (DCx) immunoreactivity in the cSVZ (see Fig. 2) was scored by a blinded observer as: none $(-)$; minimal $(+)$; moderate immunoreactivity in the cSVZ extending to several cell layers thickness infracallosally $(++)$; strong immunoreactivity in the cSVZ and infracallosal region with some cells extending into CA1 and CA3 $(+++)$; or very strong immunoreactivity in the cSVZ and infracallosal region with many cells extending into CA1 and CA3 $(++++)$. Scores are means from 4-5 per group (Numbers). d SE, days after status epilepticus.

++++ , very strong immunoreactivity in the cSVZ and infracallosal region with many cells extending into CA1 and CA3.

\section{RESULTS}

\section{SE Increases cSVZ Neural Progenitor Cell Proliferation}

We previously found that pilcocarpine-induced SE increases neurogenesis in the DG and rostral forebrain SVZ (Parent et al., 1997, 1999, 2002a). During these studies, we also noted that SE markedly increases cell proliferation in non-neurogenic regions of the hippocampus (Fig. 1A, B). We, therefore, sought to determine whether any of the newly generated hippocampal cells arose from the nearby cSVZ germinative zone, and to determine their phenotypes. The initial strategy involved labeling constitutively proliferating cells with BrdU prior to seizure induction to avoid identifying mainly reactive glia induced to proliferate by injury. A similar strategy showed that constitutively dividing cells in the DG subgranular zone are stimulated by SE to generate increased numbers of progeny (Parent et al., 1999).

We administered BrdU 2 days prior to pilocarpine treatment and examined BrdU labeling at different time points after SE. In the cSVZ and infracallosal region adjacent to the dorsal hippocampus, BrdU-immunoreactive cell numbers were not increased 1 day after SE (3 days after BrdU administration) when compared with that of saline-treated controls (data not shown). By 4-7 days after SE, however, cSVZ and infracallosal BrdU labeling increased and peaked at 10-14 days after pilocarpine treatment (Fig. 1C-F). Quantification of cSVZ BrdU-immunoreactive cells in animals 10 days after saline or pilocarpine treatment (12 days after BrdU administration) showed significantly greater numbers in pilocarpinetreated rats (cells [mean \pm SEM] : pilocarpine: $38.7 \pm 6.0$; saline: $12.9 \pm 0.4 ; P=0.01)$. Because the corpus callosum also contains proliferating cells that are putative oligodendrocyte progenitors (Gensert and Goldman,1996), we quantified BrdU-positive cell numbers in this region for comparison and 


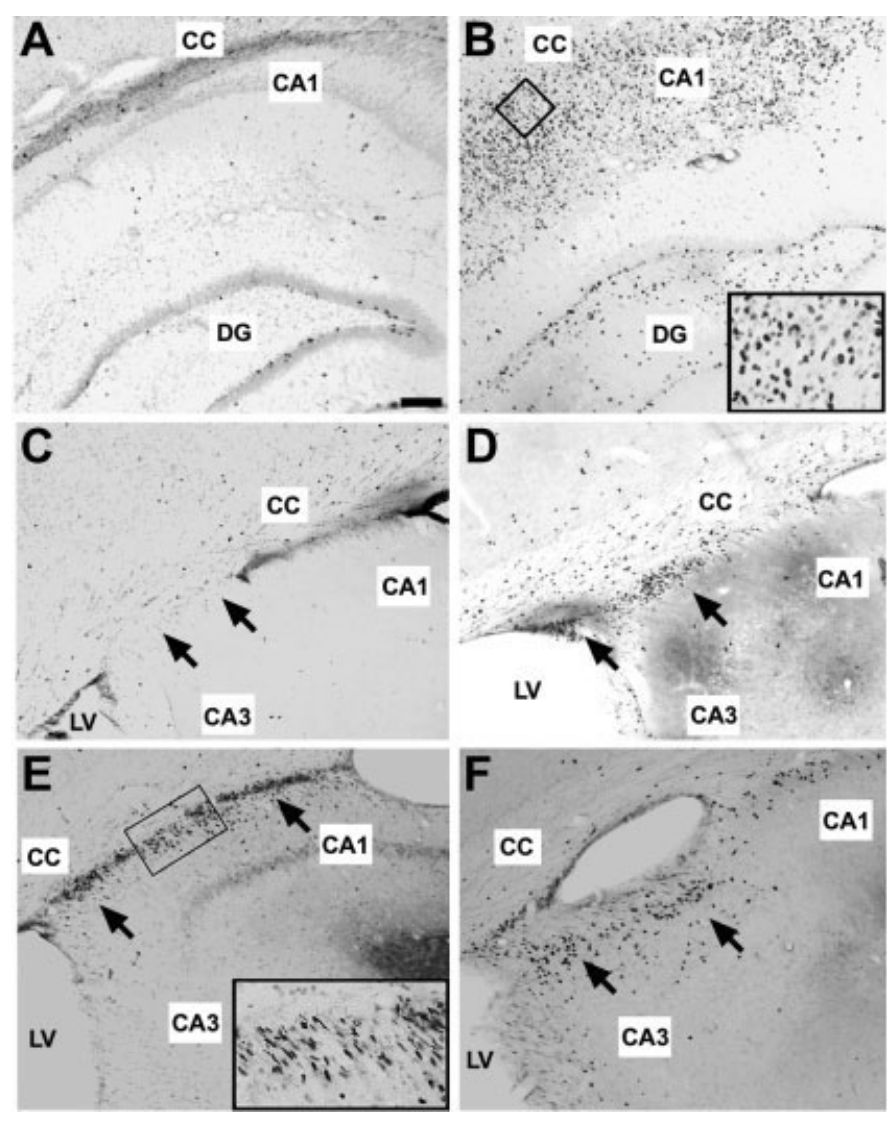

FIGURE 1. Hippocampal and cSVZ cell proliferation after pilocarpine-induced SE. Coronal sections from control $(A, C)$ and pilocarpine-treated adult rats (B, D-F) immunostained for BrdU. A, B: A representative animal given BrdU 7 days after pilocarpine and killed 14 days later shows much more BrdU labeling in the DG and CA1 region (B) when compared with that in a salinetreated control (A). C-F: cSVZ BrdU labeling in a saline-treated control $(\mathrm{C})$ and pilocarpine-treated rats $(\mathrm{D}-\mathrm{F})$ given BrdU 2 days prior to pilocarpine or saline and killed $10(\mathrm{C}-\mathrm{E})$ or $14(\mathrm{~F}) \mathrm{d}$ later (12 or 16 days after BrdU). cSVZ and infracallosal BrdU labeling (arrows) increased markedly in the pilocarpine-treated rats. Note also the fusiform nuclear shape of infracallosal cells that incorporated BrdU 12 days earlier (inset in $\mathrm{E}$ ) when compared with the rounder shape in the $\mathrm{CA1}$ region when $\mathrm{BrdU}$ was given 7 days after SE and the animal killed 14 days later (inset in B). CC, corpus callosum; Dentate Gyrus, DG; LV, lateral ventricle; CA, cornu ammonis. Scale bar $=400 \mu \mathrm{m}(\mathrm{A}, \mathrm{B}) ; 100 \mu \mathrm{m}(\mathrm{C}, \mathrm{D}, \mathrm{F}) ; 200 \mu \mathrm{m}$ (E); and $50 \mu \mathrm{m}$ (insets).

found no difference between pilocarpine- and saline-treated rats at 10 days after treatment (cells [mean \pm SEM]: pilocarpine: $29.2 \pm 6.0$; saline: $16.8 \pm 0.4 ; P=0.14$ ). These findings indicate that cells proliferating prior to $S E$ accumulate specifically in the cSVZ and infracallosal hippocampal regions, but not in the corpus callosum, another area containing proliferating cells.

\section{cSVZ Precursors Migrate to the Hippocampus After SE}

Many BrdU-positive cells found in the cSVZ after SE had fusiform-shaped nuclei, suggestive of migrating cells, and extended toward the CA1 and CA3 pyramidal cell regions (Fig. 1E). The finding of more BrdU positive cells in the hippocampus with longer time intervals after the preseizure BrdU administration (data not shown) also suggested migration to the injured hippocampus. To examine whether the cSVZ precursors were migrating, and to begin to determine their phenotypes, we labeled cells with DCx, TUC-4, and PSANCAM, markers typically expressed by migrating neuroblasts (Gleeson et al., 1999; Nacher et al., 2000, 2001; Parent et al., 2002a,b, 2005). Immunoreactivity for these markers was minimal in the cSVZ and infracallosal region of controls (Fig. 2A, C, E, Table 1, and data not shown). By contrast, cSVZ and infracallosal expression of DCx, TUC-4, and PSANCAM increased markedly after SE (Fig. 2B, D, F, G and Table 1). Many of the cells exhibited a bipolar "migratory" morphology with leading and lagging processes, and appeared to extend from the cSVZ/infracallosal region to the injured hippocampus (Fig. 2B, D). SE stimulated the expression of DCx in the cSVZ with a time course similar to that found for BrdU (Table 1).

We suspected that the immature cells putatively migrating from the cSVZ to the hippocampus were neuroblasts based on their expression of DCx, TUC-4, and PSA-NCAM. Consistent with a progenitor phenotype of the TUC-4-, DCx-, and PSANCAM-immunoreactive cells, double-labeling for BrdU and TUC-4 or PSA-NCAM showed colocalization in many cells at 10 days after pilocarpine treatment (Fig. 2F- $\mathrm{F}^{\prime \prime}$ and data not shown). However, when we double-labeled with antibodies for these markers and for the neuron-specific markers $\beta$-tubulin (TuJ1) or MAP2 (a,b and c isoforms), no cellular colocalization was apparent (data not shown). This finding is unlike our prior results that showed stroke-induced migration of DCx-immunoreactive cells from the rostral SVZ to the striatum, which strongly express $\beta$-tubulin (TuJ1) or MAP2 (Parent et al., $2002 \mathrm{~b}$ ), and findings of cSVZ neuronal progenitors migrating to the ischemia-damaged hippocampus (Nakatomi et al., 2002). Most of the cells also did not express glial fibrillary acidic protein (Fig. 2G).

We next sought further evidence regarding the possibility that the cSVZ cells migrate to the hippocampus. Retrovirus carrying a GFP or nls- $\beta$-gal reporter was injected into the cSVZ 2 days prior to pilocarpine or saline treatment, and animals were killed 11,16 , or 23 days later $(9,14$, or 21 days after SE). In controls, GFP-immunoreactive cells were restricted to the cSVZ or corpus callosum and displayed oligodendrocyte or oligodendrocyte progenitor morphologies (Fig. 3A). This finding is consistent with prior reports using similar retroviral reporter injections into the SVZ of juvenile rats (Levison et al., 1993). After pilocarpine-induced SE, many more cells were labeled and they appeared in the hippocampus in addition to the cSVZ and corpus callosum (Fig. 3B, C). No GFP-labeled cells in controls or pilocarpine treated rats appeared in cortex or other subcortical regions. Taken together with the data described earlier, these results provide strong evidence that cSVZ progenitors migrate to the injured hippocampus after pilocarpine-induced SE. 


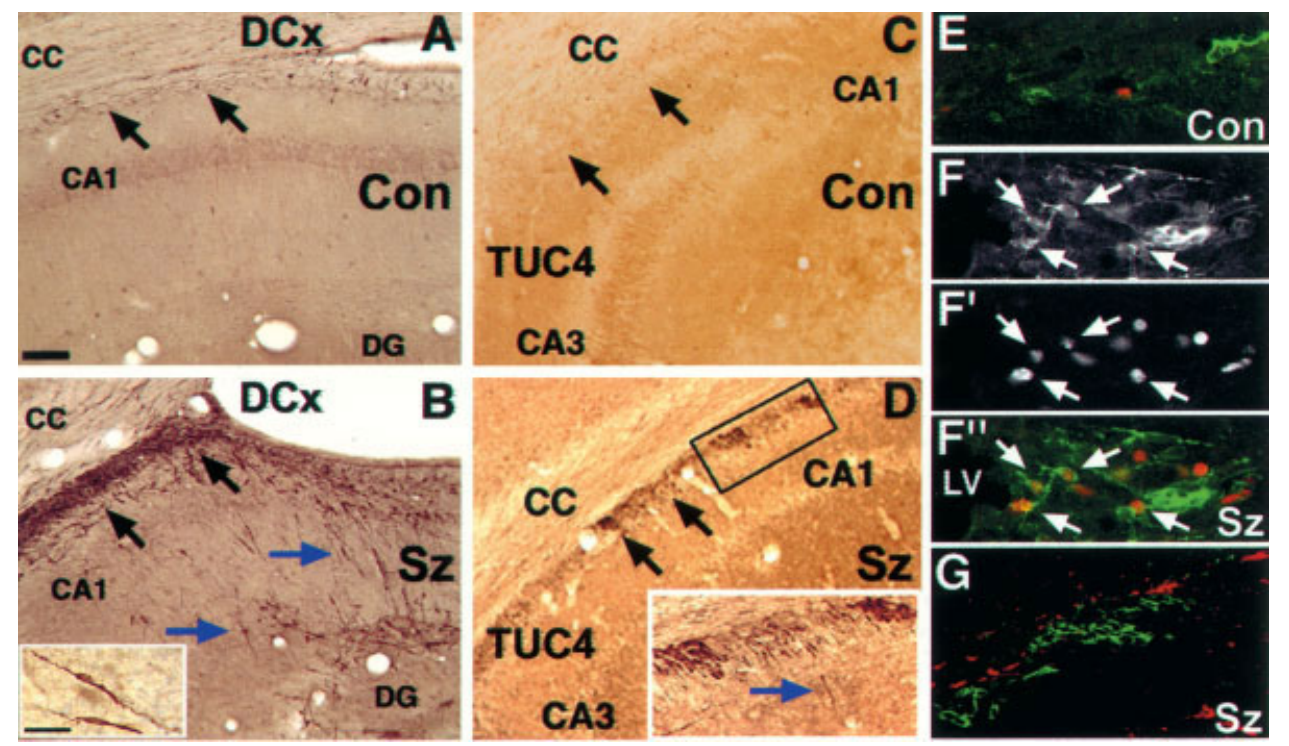

FIGURE 2. Immature neural marker expression in the cSVZ/ infracallosal region and hippocampus after SE. A-D: Immunostaining for DCx $(\mathrm{A}, \mathrm{B})$ or TUC-4 $(\mathrm{C}, \mathrm{D})$ in coronal sections from animals 14 days after saline $(\mathrm{Con} ; \mathrm{A}, \mathrm{C})$ or pilocarpine $(\mathrm{Sz} ; \mathrm{B}, \mathrm{D})$ treatment. Note the marked increase in DCx and TUC-4 expression in cSVZ/infracallosal (black arrows) and hippocampal regions after SE $(B, D)$ when compared with the minimal or no expression in the controls (A, C). Blue arrows and insets show immunolabeled cells with "migratory" morphologies extending from the cSVZ all the way to the hippocampal fissure (B). E-F", Confocal images of BrdU (red)/TUC-4 (green) double labeling in cSVZ 14 days after saline (E) or pilocarpine $\left(\mathrm{F}-\mathrm{F}^{\prime \prime}\right)$ treatment. TUC-4+ $(\mathrm{F})$, BrdU+ $\left(F^{\prime}\right)$ and double-labeled $\left(F^{\prime \prime}\right)$ cells (arrows) are increased after SE (compare $F^{\prime \prime}$ with E). G: Double labeling for PSA-NCAM (green) and GFAP (red) in the cSVZ/infracallosal region 14 days after SE shows many PSA-NCAM+ cells but little double labeling. CC, corpus callosum; DG, DG; CA, cornu ammonis; LV, lateral ventricle. Scale bar $=100 \mu \mathrm{m}(\mathrm{A}-\mathrm{D})$ and $25 \mu \mathrm{m}(\mathrm{E}-\mathrm{G}) ; 30 \mu \mathrm{m}$ (inset in B), and $75 \mu \mathrm{m}$ (inset in D). [Color figure can be viewed in the online issue, which is available at www.interscience.wiley.com.]

\section{cSVZ-Derived Precursors Differentiate Exclusively Into Glia in the Injured Hippocampus}

The phenotypes of cSVZ cells migrating to the hippocampus after SE were studied next. Because the retroviral-GFP reporter fills the cell bodies and processes, we carefully examined cell morphology as an initial assessment of the different cell phenotypes. Cells expressing the GFP reporter all exhibited glial mor- phologies, both astrocytic and oligodendrocytic (Figs. 3 and $4 \mathrm{~A}, \mathrm{E})$. No neuronal-appearing GFP-labeled cells were found. We then double or triple labeled for GFP or $\beta$-gal and glial or neuronal markers. GFP-positive cells in controls and pilocarpine-treated rats coexpressed MBP and GFAP in the corpus callosum and hippocampus (Fig. 4A-H). Double-labeling for $\beta$ gal and the neuronal markers NeuN, NF-L, MAP2, or neuronspecific $\beta$-tubulin showed no colocalization of signal in cSVZ, corpus callosum, or hippocampal cells expressing the retroviral
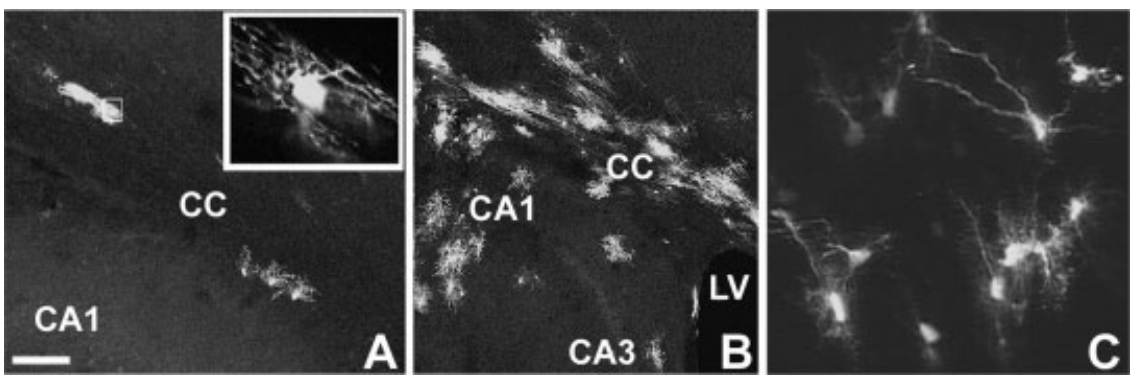

FIGURE 3. Cells labeled by cSVZ retroviral reporter injections migrate to the hippocampus after SE. GFP+ cells in coronal sections from rats 21 days after saline $(A)$ or pilocarpine treatment $(B, C)$. LNIT-GFP retroviral reporter was injected into the right cSVZ 2 days prior to treatment. In the control, all labeled cells are in the corpus callosum and have oligodendrocytic morphology (inset in A). Prolonged seizures increase the number of GFP-labeled cells and induce cell migration to the hippocampus as well as corpus callosum $(B, C)$. Labeled cells have both astrocytic and oligodendroglial morphologies after SE. Panel $\mathrm{C}$ shows a higher magnification view of hippocampal cells in a different section from the same rat as in B. Medial is to the left and dorsal to the top in all panels. CC, corpus callosum; CA, cornu ammonis; LV, lateral ventricle. Scale bar $=150 \mu \mathrm{m}(\mathrm{A}, \mathrm{B}) ; 40 \mu \mathrm{m}(\mathrm{C}) ; 20 \mu \mathrm{m}$ (inset in A). 

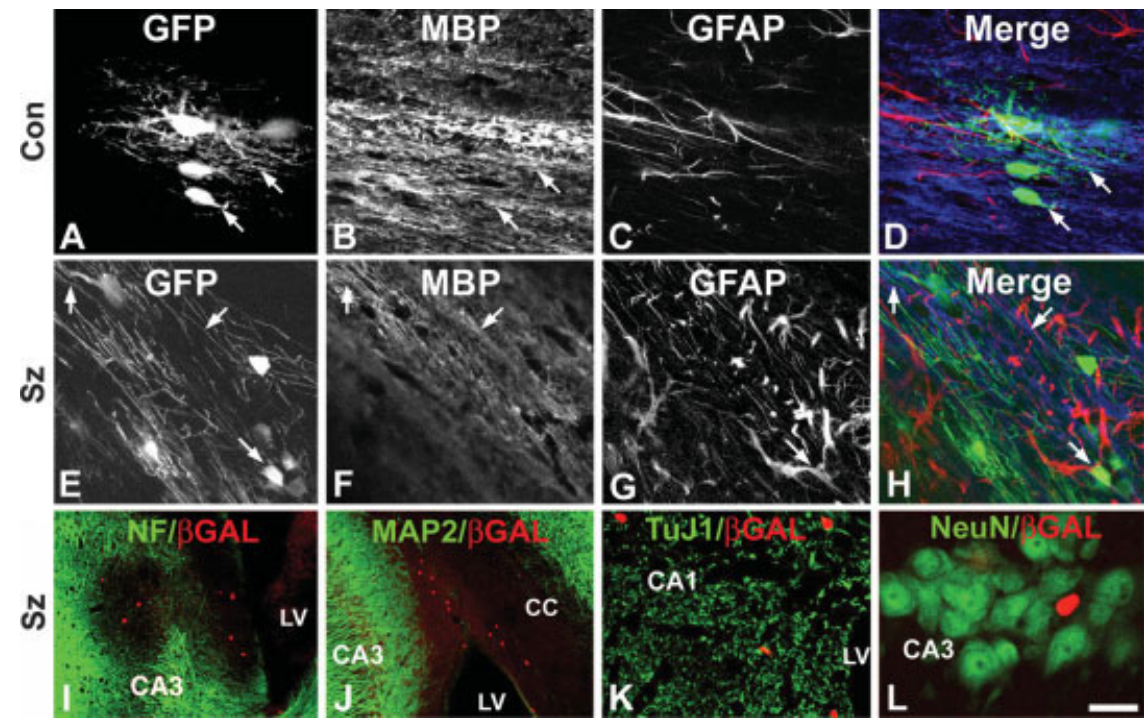

FIGURE 4. Phenotypes of the progeny of retroviral reporterlabeled cells originating in the cSVZ. A-H, Triple immunofluorescence confocal microscopic images from control (Con; A-D) and pilocarpine-treated $(S z ; E-H)$ rats 14 days after treatment (16 days after retrovirus injection) show GFP-positive cells (A, E) that express MBP (arrows in B, E) or GFAP (arrow in G) in the corpus callosum (A-D) or pericallosal region extending into the hippocampus $(E-H)$. Merged images are shown in D and H. I-L: Con-

focal microscopic images of double labeling for $\beta$-gal (red) and neuronal markers (green) 9 (I-K) or 14 days (L) after pilocarpine treatment (11 or 16 days after retroviral-nls- $\beta$-gal reporter injection into the right $c S V Z$ ). No $\beta$-gal+ cells expressed any of the neuronal markers described in the panels (see text for details). LV, lateral ventricle; $C C$, corpus callosum; CA, cornu ammonis. Scale bar $=30 \mu \mathrm{m}(\mathrm{A}-\mathrm{H}, \mathrm{L}) ; 200 \mu \mathrm{m}(\mathrm{I}, \mathrm{J}) ; 100 \mu \mathrm{m}(\mathrm{K})$.

nls- $\beta$-gal reporter (Fig. $4 \mathrm{I}-\mathrm{L}$ ). The findings therefore show that cSVZ cells induced to migrate to the injured hippocampus after SE differentiate into glia but not neurons.

\section{DISCUSSION}

The present results indicate that the cSVZ is a third germinative zone in the adult, in addition to the rostral SVZ and DG, that is activated by pilocarpine-induced SE. Similar to the DG and SVZ-olfactory bulb pathway (Parent et al., 1997, 2002a, 2005), prolonged seizures increase cSVZ cell proliferation and alter neural progenitor migration. Instead of migrating exclusively into the corpus callosum as was found in control adult rats, however, a portion of the cSVZ progenitors at dorsal hippocampal levels was diverted to the injured hippocampus (Fig. 5). Unlike neural progenitors in the rostral SVZ and DG that differentiate nearly exclusively into neurons in the intact brain or after SE, cSVZ precursors that migrate to the corpus callosum and hippocampus differentiate into glia. Neuronal replacement, therefore, appears to be absent in the hippocampal pyramidal cell layer after seizure-induced injury in the adult.

Why should cSVZ progenitors give rise to neurons after transient global ischemia but only glia after SE? The most likely explanation is that the modes of cell death are different after these types of injuries. The ischemia models in which CA1 pyramidal cell regeneration is found cause a delayed apoptotic pyramidal cell death (Nakatomi et al., 2002; Bendel et al., 2005). Pilocarpine-induced SE, on the other hand, involves a mixed form of cell death that includes a significant

necrotic component (Fujikawa et al., 1999, 2002; Weise et al., 2005). Macklis and colleagues have shown that transplanted or endogenous neural progenitors in adult mouse brain give rise to cortical pyramidal neurons after a toxin-induced apoptotic cell death but not after necrosis caused by kainic acid injection (Snyder et al., 1997; Magavi et al., 2000). These differences may relate to inhibitory factors generated after necrosis, or absence of necessary growth or survival factors in necrotic envi-

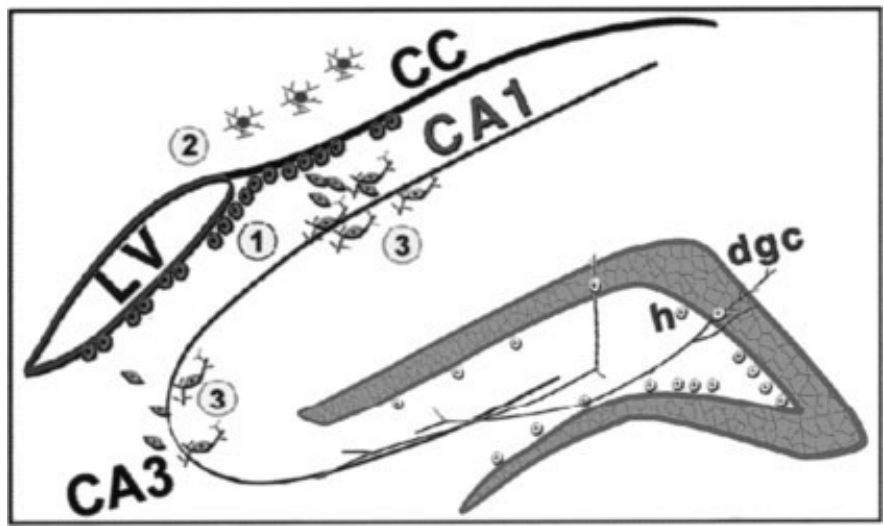

FIGURE 5. Model of cSVZ neural progenitor behavior after seizure-induced hippocampal injury. Adult neural progenitors proliferate in the cSVZ (1) and normally migrate into the corpus callosum (CC) to form oligodendrocytes or oligodendrocyte progenitors (2). After SE, cSVZ progenitors migrate to the injured hippocampus and differentiate into glial cells (3). SE simultaneously increases dentate granule cell neurogenesis in the dentate hilus (h) and granule cell layer $(\mathrm{dgc})$. 
ronments that are stimulated only by apoptosis (Wang et al., 1998). Another possibility is that ischemic injury upregulates the expression of a more "neurogenic" repertoire of growth or differentiation factors than does pilocarpine-induced SE.

Our findings also highlight the lack of specificity of putative "neuronally-specified" progenitor markers such as DCx or TUC-4 (Jin et al., 2004; Couillard-Despres et al., 2005), as has been recognized previously for TUC-4/CRMP-4 (Nacher et al., 2000). Prior investigations of the DG, rostral SVZ-olfactory bulb pathway and striatum after seizure- or focal ischemiainduced injury showed that DCx, TUC-4 and PSA-NCAM expression reliably identified immature neurons that also were immunoreactive for neuron-specific $\beta$-tubulin and MAP2 (Parent et al., 1997, 1999, 2002a,b). Progenitors in the cSVZ that express DCx, TUC-4, and PSA-NCAM after SE, however, are glial lineage cells. Studies of SVZ progenitors in the intact neonatal and juvenile rat suggest that many of these progenitors migrate into subcortical white matter and cortex where they give rise mainly to oligodendroglial precursors, and the remainder to astrocytes (Levison et al., 1993, 1999; Gensert and Goldman, 1996). Further investigation is necessary to determine the specific classes of glial progenitors labeled by putative "neuroblast" markers in the adult, and whether the same SVZ progenitors give rise to both neurons and glia.

We cannot exclude the possibility that some progeny of cSVZ cells dividing after SE, at time points other than those used in the present study for BrdU or retroviral reporter administration, gave rise to neurons. DCX-, TUC-4-, or PSANCAM-immunoreactive cells destined to become neurons may fail to survive in the injured hippocampus. This possibility is unlikely given that the cells did not express the immature neuron-specific markers class III $\beta$-tubulin or MAP2c, and because we found no double-labeled neurons in the pyramidal cell layer in animals injected with BrdU 7 days after SE and killed 2 weeks later (data not shown). Certainly the known lack of hippocampal regeneration after pilocarpine-induced SE excludes a significant degree of neurogenesis with long-term survival of newly formed neurons. Our findings after cSVZ retroviral reporter injections also suggest that potential newborn neurons, if any, do not arise from the constitutively dividing cells in the cSVZ, although our retroviral reporters would not have labeled quiescent cells that could be recruited after seizure-induced injury. Nonetheless, these results indicate that the majority, if not all, of the cells recruited from the cSVZ to sites of SEinduced hippocampal damage are glial progenitors.

The signals that lead to aberrant cSVZ glial progenitor migration and the effects of ectopic gliogenesis in the epileptic hippocampus are unknown. Seizures upregulate a number of growth factors that have been shown to influence glial progenitor migration, such as basic fibroblast growth factor and vascular endothelial growth factor (Faber-Elman et al., 1996; Holland and Varmus, 1998; de Castro and Bribián, 2005; Hagihara et al., 2005). Various axon guidance, cell adhesion, and extracellular matrix molecules known to stimulate glial progenitor migration might be involved as well (de Castro and Bribián, 2005; Wang et al., 2005). The result of ectopic gliogenesis in the injured hippocam- pus is even less clear. Although they may contribute to repair, recent work suggests that immature astrocytes may promote an epileptic phenotype. Two groups have identified astrocytes with immature features in the sclerotic CA1 region of human hippocampi resected to treat intractable mTLE but not in nonsclerotic hippocampi (Hinterkeuser et al., 2000; Kivi et al., 2000). These glia possess barium-insensitive potassium channels typical of immature glia. The potassium channels buffer potassium poorly such that, unlike those in mature astrocytes, they may lead to seizure generation in the setting of excessive neuronal depolarization. Although speculative, it is possible that the immature glia arise from the cSVZ during epileptogenesis and remain immature or continue to accumulate because of recurrent seizures. A better understanding of mechanisms that regulate neural stem cells in the postnatal brain may therefore lead to novel treatments that modulate progenitors to block epileptogenesis and promote neural repair.

\section{REFERENCES}

Altman J, Das GD. 1965. Autoradiographic and histological evidence of postnatal hippocampal neurogenesis in rats. J Comp Neurol 124:319-335.

Altman J. 1969. Autoradiographic and histological studies of postnatal neurogenesis. IV. Cell proliferation and migration in the anterior forebrain, with special reference to persisting neurogenesis in the olfactory bulb. J Comp Neurol 137:433-458.

Arvidsson A, Collin T, Kirik D, Kokaia Z, Lindvall O. 2002. Neuronal replacement from endogenous precursors in the adult brain after stroke. Nat Med 8:963-970.

Bayer SA. 1983. 3H-thymidine-radiographic studies of neurogenesis in the rat olfactory bulb. Exp Brain Res 50:329-340.

Bendel O, Bueters T, von Euler M, Ove Ogren S, Sandin J, von Euler G. 2005. Reappearance of hippocampal CA1 neurons after ischemia is associated with recovery of learning and memory. J Cereb Blood Flow Metab May 25; [Epub ahead of print].

Bengzon J, Kokaia Z, Elmer E, Nanobashvili A, Kokaia Z, Lindvall O. 1997. Apoptosis and proliferation of DG neurons after single and intermittent limbic seizures. Proc Natl Acad Sci USA 94: $10432-10437$.

Cameron HA, Woolley CS, McEwen BS, Gould E. 1993. Differentiation of newly born neurons and glia in the DG of the adult rat. Neuroscience 56:337-344.

Couillard-Despres S Winner B, Schaubeck S, Aigner R, Vroemen M, Weidner N, Bogdahn U, Winkler J, Kuhn HG, Aigner L. 2005. Doublecortin expression levels in adult brain reflect neurogenesis. Eur J Neurosci 21:1-14.

Dashtipour K, Tran PH, Okazaki MM, Nadler JV, Ribak CE. 2001. Ultrastructural features and synaptic connections of hilar ectopic granule cells in the rat DG are different from those of granule cells in the granule cell layer. Brain Res 890:261-271.

de Castro F, Bribián A. 2005. The molecular orchestra of the migration of oligodendrocyte precursors during development. Brain Res Rev 49:227-241.

Eriksson PS, Perfilieva E, Bjork-Eriksson T, Alborn AM, Nordborg C, Peterson DA, Gage FH. 1998. Neurogenesis in the adult human hippocampus. Nature Med 4:1313-1317.

Faber-Elman A, Solomon A, Abraham JA, Marikovsky M, Schwartz M. 1996. Involvement of wound-associated factors in rat brain astrocyte migratory response to axonal injury: in vitro simulation. J Clin Invest 97:162-171. 
Fujikawa DG, Shinmei SS, Cai B. 1999. Lithium-pilocarpine-induced status epilepticus produces necrotic neurons with internucleosomal DNA fragmentation in adult rats. Eur J Neurosci 11:1605-1614.

Fujikawa DG, Ke X, Trinidad RB, Shinmei SS, Wu A. 2002. Caspase3 is not activated in seizure-induced neuronal necrosis with internucleosomal DNA cleavage. J Neurochem 83:229-240.

Gensert JM, Goldman JE. 1996. In vivo characterization of endogenous proliferating cells in adult rat subcortical white matter. Glia 17:39-51.

Gleeson JG, Lin PT, Flanagan LA, Walsh CA. 1999. Doublecortin is a microtubule-associated protein and is expressed widely by migrating neurons. Neuron 23:257-271.

Gould E, Tanapat P, McEwen BS, Flugge G, Fuchs E. 1998. Proliferation of granule cell precursors in the DG of adult monkeys is diminished by stress. Proc Natl Acad Sci USA 95:3168-3171.

Gray WP, Sundstrom LE. 1998. Kainic acid increases the proliferation of granule cell progenitors in the DG of the adult rat. Brain Res 790:52-59.

Hagihara H, Hara M, Tsunekawa K, Nakagawa Y, Sawada M, Nakano K. 2005. Tonic-clonic seizures induce division of neuronal progenitor cells with concomitant changes in expression of neurotrophic factors in the brain of pilocarpine-treated mice. Mol Brain Res Jul 12; [Epub ahead of print]

Hinterkeuser S, Schroder W, Hager G, Seifert G, Blumcke I, Elger CE, Schramm J, Steinhauser C. 2000. Astrocytes in the hippocampus of patients with TLE display changes in potassium conductances. Eur J Neurosci 12:2087-2096.

Holland EC, Varmus HE. 1998. Basic fibroblast growth factor induces cell migration and proliferation after glia-specific gene transfer in mice. Proc Natl Acad Sci USA 95:1218-1223.

Jin K, Peel AL, Mao XO, Xie L, Cottrell BA, Henshall DC, Greenberg DA. 2004. Increased hippocampal neurogenesis in Alzheimer's disease. Proc Natl Acad Sci USA 101:343-347.

Kaplan MS, Hinds JW. 1977. Neurogenesis in adult rat: electron microscopic analysis of light radioautographs. Science 197:10921094.

Kivi A, Lehmann TN, Kovacs R, Eilers A, Jauch R, Meencke HJ, von Deimling A, Heinemann U, Gabriel S. 2000. Effects of barium on stimulus-induced rises of $[\mathrm{K}+]_{\mathrm{o}}$ in human epileptic nonsclerotic and sclerotic hippocampal area CA1. Eur J Neurosci 12:20392048.

Kornack DR, Rakic P. 1999. Continuation of neurogenesis in the hippocampus of the adult macaque monkey. Proc Natl Acad Sci USA 96:5768-5773.

Kuhn HG, Dickinson-Anson H, Gage FH. 1996. Neurogenesis in the DG of the adult rat: age-related decrease of neuronal progenitor proliferation. J Neurosci 16:2027-2033.

Levison SW, Chuang C, Abramson BJ, Goldman JE. 1993. The migrational patterns and developmental fates of glial precursors in the rat subventricular zone are temporally regulated. Development 119:611-622.

Levison SW, Young GM, Goldman JE. 1999. Cycling cells in the adult rat neocortex preferentially generate oligodendroglia. J Neurosci Res 57:435-446.

Lois C, Alvarez-Buylla A. 1994. Long-distance neuronal migration in the adult mammalian brain. Science 264:1145-1148.

Luskin MB. 1998. Neuroblasts of the postnatal mammalian forebrain: their phenotype and fate. J Neurobiol 36:221-233.

Magavi SS, Leavitt BR, Macklis JD. 2000. Induction of neurogenesis in the neocortex of adult mice. Nature 405:951-955.

Nacher J, Rosell DR, McEwen BS. 2000. Widespread expression of collapsin response-mediated protein 4 in the telencephalon and other areas of the adult rat central nervous system. J Comp Neurol 424:628-639.

Nacher J, Crespo C, McEwen BS. 2001. Doublecortin expression in the adult rat telencephalon. Eur J Neurosci 14:629-644.

Nakatomi H, Kuriu T, Okabe S, Yamamoto S, Hatano O, Kawahara N, Tamura A, Kirino T, Nakafuku M. 2002. Regeneration of hippocampal pyramidal neurons after ischemic brain injury by recruitment of endogenous neural progenitors. Cell 110:429-441.

Ory DS, Neugeboren BA, Mulligan RC. 1996. A stable humanderived packaging cell line for production of high titer retrovirus/ vesicular stomatitis virus $G$ pseudotypes. Proc Natl Acad Sci USA 93:11400-11406.

Parent JM, Yu TW, Leibowitz RT, Geschwind DH, Sloviter RS, Lowenstein DH. 1997. Dentate granule cell neurogenesis is increased by seizures and contributes to aberrant network reorganization in the adult rat hippocampus. J Neurosci 17:3727-3738.

Parent JM, Janumpalli S, McNamara JO, Lowenstein DH. 1998. Increased dentate granule cell neurogenesis following amygdala kindling in the adult rat. Neurosci Lett 247:9-12.

Parent JM, Tada E, Fike JR, Lowenstein DH. 1999. Inhibition of dentate granule cell neurogenesis with brain irradiation does not prevent seizure-induced mossy fiber synaptic reorganization in the rat. J Neurosci 19:4508-4519.

Parent JM, Valentin VV, Lowenstein DH. 2002a. Prolonged seizures increase proliferating neuroblasts in the adult rat subventricular zone-olfactory bulb pathway. J Neurosci 22:3174-3188.

Parent JM, Vexler ZS, Gong C, Derugin N, Ferriero DM. 2002b. Rat forebrain neurogenesis and striatal neuron replacement after focal stroke. Ann Neurol 52:802-813.

Parent JM, Elliott RC, Pleasure SJ, Barbaro NM, Lowenstein DH. 2005. Aberrant seizure-induced neurogenesis in experimental TLE. Ann Neurol Oct 31; [Epub ahead of print].

Picard-Riera N, Nait-Oumesmar B, Baron-Van Evercooren A. 2004. Endogenous adult neural stem cells: limits and potential to repair the injured central nervous system. J Neurosci Res 76:223-231.

Scharfman HE, Goodman JH, Sollas AL. 2000. Granule-like neurons at the hilar/CA3 border after status epilepticus and their synchrony with area CA3 pyramidal cells: functional implications of seizureinduced neurogenesis. J Neurosci 20:6144-6158.

Scott BW, Wang S, Burnham WM, De Boni U, Wojtowicz JM. 1998. Kindling-induced neurogenesis in the DG of the rat. Neurosci Lett 248:73-76.

Snyder EY, Yoon C, Flax JD, Macklis JD. 1997. Multipotent neural precursors can differentiate toward replacement of neurons undergoing targeted apoptotic degeneration in adult mouse neocortex. Proc Natl Acad Sci USA 94:11663-11668.

Turski WA, Cavalheiro EA, Schwarz M, Czuczwar SJ, Kleinrok Z, Turski L. 1983. Limbic seizures produced by pilocarpine in rats: behavioral, electroencephalographic and neuropathological study. Behav Brain Res 9:315-335.

Wang Y, Sheen VL, Macklis JD. 1998. Cortical interneurons upregulate neurotrophins in vivo in response to targeted apoptotic degeneration of neighboring pyramidal neurons. Exp Neurol 154:389-402.

Wang M, Kong Q, Gonzalez FA, Sun G, Erb L, Seye C, Weisman GA. 2005. P2Y nucleotide receptor interaction with $\alpha$ integrin mediates astrocyte migration. J Neurochem Aug 31; [Epub ahead of print].

Weise J, Engelhorn T, Dorfler A, Aker S, Bahr M, Hufnagel A. 2005. Expression time course and spatial distribution of activated caspase3 after experimental status epilepticus: contribution of delayed neuronal cell death to seizure-induced neuronal injury. Neurobiol Dis $18: 582-590$. 